\title{
Fizik Tedavi ve Rehabilitasyon Uygulamalarında Kullanılabilecek Anlık Denge Kontrolü ve Biyolojik Geri Bildirimi Sağlayan Giyilebilir Sensör Tasarımı
}

\author{
Hande Argunşah Bayram๑, Begüm Yalçın®
}

Acıbadem Üniversitesi, Mühendislik Fakültesi, İstanbul, Türkiye

Hande Argunşah Bayram, Ph.D. Begüm Yalçın, MSC

Iletişim:

Ph.D. Hande Argunşah Bayram

Acıbadem Üniversitesi, Mühendislik Fakültesi, İstanbul, Türkiye

Tel: +902165004145

E-Posta: hande.argunsah@gmail.com

Gönderilme Tarihi : 04 Aralık 2018

Revizyon Tarihi : 100 cak 2019

Kabul Tarihi : : 04 Şubat 2019

\section{ÖZET}

Denge ve performansın iyileştirilmesi için motor bilgilerinin arttırılması yoluyla statik ve dinamik görevlerde motor kontrolünü destekleyen biyolojik geri besleme, rehabilitasyon sırasında hastalara, fizik tedavi ve rehabilitasyon uzman doktorları ile fizyoterapistlere yardımcı olmak için kullanılmaktadır. Postürel kontrol ve denge eksikliği, günlük yaşam aktiviteleri sırasında hastaların mobilizasyonu ve bağımsız performansları üzerinde en büyük etkiye sahiptir. Bir bireyin "statik" dengesi, sabit dururken veya bir seferde tek bir görevi yerine getirirken kabul edilebilir olsa da; "dinamik" denge sorunları, mobilizasyon sırasında veya bir seferde birden fazla görev yaparken ortaya çıkabilir. Bu nedenle, hastanın gerçek zamanlı dinamik dengesinin farkında olmak hem hasta hem de uzman doktor ile fizyoterapist için önemlidir. Bu araştırmada, ortopedik ve nöromusküler hastalıkların fizik tedavi ve rehabilitasyonu sırasında kullanılmak üzere tasarlanan dokunsal ve görsel biyolojik geri bildirim mekanizması geliştirilmiştir.

Anahtar sözcükler: Denge, giyilebilir, biyolojik geri bildirim

REAL-TIME BALANCE FEEDBACK MECHANISM FOR ORTHOPEDIC AND NEUROMUSCULAR DISEASES REHABILITATION PRACTICES

\section{ABSTRACT}

Biological feedback, which favors motor control in static and dynamic tasks via augmenting motor information for improving balance and performance, is used to assist patients and clinicians during rehabilitation. Lack of balance and postural control has the greatest impact on patients' mobilization and independent performance during the activities of daily living. Although an individual's "static" balance is acceptable while standing still or performing a single task at a time; "dynamic" balance problems may become apparent during mobilization or while doing multiple tasks at a time. Therefore, being aware of the real-time dynamic balance of the patient is critical for both the patient and the physical therapist. This investigation developed a tactile and visual biological feedback mechanism intended to be used during the orthopedic and neuromuscular disease rehabilitation.

Keywords: balance, wearable, biological feedback

$\mathbf{Y}$ ürüyüş simetrisi sağ ve sol ekstremiteler arasındaki kinematik ve kinetik parametrelerin oranı olarak tanımlanmaktadır (1). Simetri yokluğu mobilizasyon esnasında kas kasılması, denge ve biyomekanik parametrelerde farkIılıklar ile sonuçlanır. Bu nedenle de olası yaralanmalar için bir risk faktörü olarak tanımlanmaktadır. Postürel kontrol ve denge optimal mobilizasyon için gereklidir ve 
kaslar ile bağların kompleks senkronizasyonunu gerektirir (1). Düzensiz kalp atım hızı ve vücut kütle merkezi üzerinde önemli etkiye sahip olan denge bozukluğu, yorgunluğun ve egzersizin erken sonlandırılmasının temel faktörlerinden biridir (2).

Biyolojik geri bildirim hastalara gerçek zamanlı olarak, aksi halde bilinemeyen biyolojik bilgiyi (ölçülen değişkenle ilgili, uyarlanmış bir işitsel sinyal, görsel veya dokunsal geri bildirim) sağlama tekniğidir. Fizik tedavi ve rehabilitasyon sırasında hastalara ve rehabilitasyon ekibine geri bildirim sağlanması sürecin etkinliğini artırmaktadır, çünkü sağlanan gerçek zamanlı bilgi ile işlevsel görevler sırasında doğruluk ve rehabilitasyonda hasta katılımı artırılabilmektedir (3).

Biyolojik geri bildirim, motivasyonu artırmak, fizik tedavi ve rehabilitasyon süreçleri sırasında bireyin fizyolojik, kinetik ve kinematik değişkenlerini düzenlemek için kullanılmaktadır. Uyarılmış işitsel, görsel veya dokunsal gerçek zamanlı geri bildirim olarak eş zamanlı bilgi sağlamanın bir yöntemidir ve yürüyüş desenini geliştirerek ağrıda azalma ve fonksiyonel becerilerde iyileşme sağladığı daha önceki çalışmalarda belirlenmiştir (4-7). Bilgi teknolojisinin kullanımı, hastaya özgü ve etkin egzersiz ve tedavi programlarını tasarlamak ve niceliksel bilgileri kullanmak için fizik tedavi süreçlerine dâhil edilmiştir. Amaç, gerçek zamanlı fizyolojik ve biyomekanik durumun farkındalığını devam ettirerek hastanın aktiviteyi sürdürme konusundaki performansını, uyumluluğunu ve istekliliğini arttırmaktır (8). Ayrıca, bireyin vücuda ait bilgileri biyomekanik girdiyle ilişkilendirmesine izin verir. Olası yaralanma riskini en aza indirmek, fiziksel ve zihinsel rutini dengeleyerek motivasyonu ve motor becerisini geliştirmek için kullanılmaktadır (9-12). Önceki çalışmalar, sporcuların motor beceri kazanım düzeylerinin biyolojik geri bildirimle artırılabileceğini göstermiştir (13-15).

Propriosepsiyon, vücudun çeşitli görsel, vestibüler ve proprioseptif girişlerden gelen biyolojik bilgilerle postürü stabilize etmek için uzayda hareket, denge ve konum hissi olarak tanımlanmaktadır (16). Statik propriyoseptif bilgi postürel oryantasyonun, dinamik proprioseptif bilgi ise postürel stabilitenin kontrolünü içermektedir (17). Bu bilgilerin doğru bir şekilde bilinmesi, vücut ağırlığının doğru yüklenmesi ve normal ambulasyonun sürdürülmesi için gereklidir. Stabilite ve dengeyi sağlama yeteneği, günlük yaşam aktivitelerinde ve nörolojik ve ortopedik hastalıkların fizik tedavi uygulamalarında fonksiyonel bağımsızlık için kritik öneme sahiptir.
Denge ve performansın iyileştirilmesi için motor bilgilerin arttırılması yoluyla statik ve dinamik görevlerde motor kontrolünü destekleyen biyolojik geri besleme, rehabilitasyon sırasında hastalara, fizik tedavi ve rehabilitasyon uzman hekimleri ile fizyoterapistlere anlık fizyolojik bilgi sağlamak için kullanılmaktadır. Bu çalışma kapsamında denge kaybının sıklıkla gözlemlendiği ortopedik ve nöromusküler hastalıkların rehabilitasyonu sırasında kullanılmak üzere; hastanın anlık denge durumunu takip etme ve dengenin kaybedildiği anlarda hastayı titreşim yoluyla uyararak bozulan dengenin yeniden kazanılmasını sağlama amacıyla dokunsal, sensör üzerindeki led lambalar yoluyla da dengenin kaybedildiği anlarda fizik tedavi ekibine görsel biyolojik geri bildirim veren giyilebilir bir denge sensörü geliştirilmiştir. Ayrıca tedavi sonunda hastanın dengesinin kaç kez ve hangi yön/yönlerde bozulduğunu gösteren bir rapor elde edilmekte, bu da denge kontrolünün tedavi boyunca takip edilerek nicel olarak raporlanmasını ve daha önceki seanslarla kıyaslanarak hasta takibinin nicel veriler ışığında yapılmasını sağlamaktadır. Bu makale geliştirilen biyolojik geri bildirim mekanizmasının teknik detaylarını ve sağlıklı katılımcılar üzerinde yapılan doğrulama testlerinin sonuçlarını kapsamaktadır.

\section{Yöntemler}

Giyilebilir olarak tasarlanan ve girişimsel olmayan biyolojik geri bildirim mekanizması vücudun bel bölgesine yerleştirilen kemer ile sternuma yerleştirilen hareket işlemcisinden (MPU) (üç eksenli ivmeölçer, üç eksenli jiroskop ve üç eksenli manyetometre ile dokuz eksenli sensör) oluşmaktadır (Şekil 1). Sensör hastanın vücut kütle merkezini

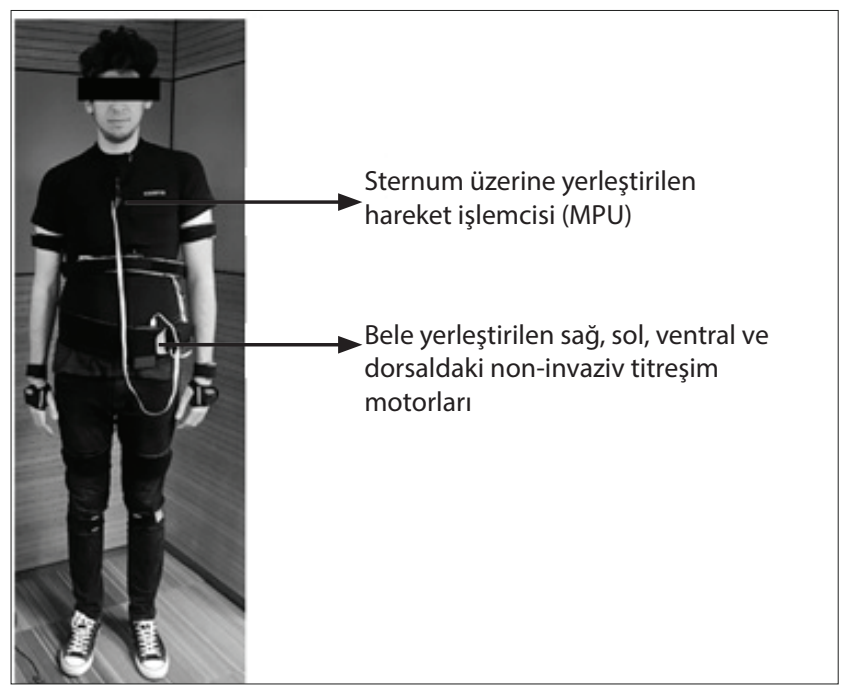

Şekil 1. Dokunsal ve görsel anlık denge geri bildirim sensörünün vücut üzerine yerleştirilmesi. 
tedavi süresince fizyoterapist tarafından belirlenen eşik değere göre dengede tutmasını sağlamakta, dengenin bozulduğu anlarda da postürün düzeltilmesini sağlamak amacıyla, hasta dengesinin eşik değerini aştığı yerdeki titreşim motor ya da motorlarını aktive ederek hastaya dokunsal uyarı (geri bildirim) vermektedir. Bu geri bildirim tek yönde dengenin bozulduğu anlarda tek, ara yönde dengenin bozulduğu durumlarda ise frontal düzlemdeki titreşim motorlarından biri ile sagittal düzlemdeki titreşim motorlarından birinin ikili kombinasyonları şeklinde aktive edilmesi ile gerçekleştirilmekte ve hastaya anlık olarak bildirilmektedir. Aynı zamanda her bir titreşim motorunun üzerine yerleştirilen led lamba sayesinde aktive olan ve o an titreşim yoluyla hastaya dokunsal geri bildirim sağlayan motorun belirlenmesi ve fizik tedavi ekibine de görsel geri bilirim yoluyla bildirilmesi için bir algoritma geliştirilmiştir. Kişinin konum bilgisini sternuma takılan dokuz eksenli sensörden alarak Raspberry $\mathrm{Pi}^{\circ} \mathrm{da}$ (Raspberry $\mathrm{Pi}$ Foundation, https://www.raspberrypi.org) işlenen bu algoritmayı oluşturan akış şeması Şekil 2'de gösterilmiştir. Tedavi sonunda hastanın denge kontrolünü gösteren bir rapor elde edilmektedir.

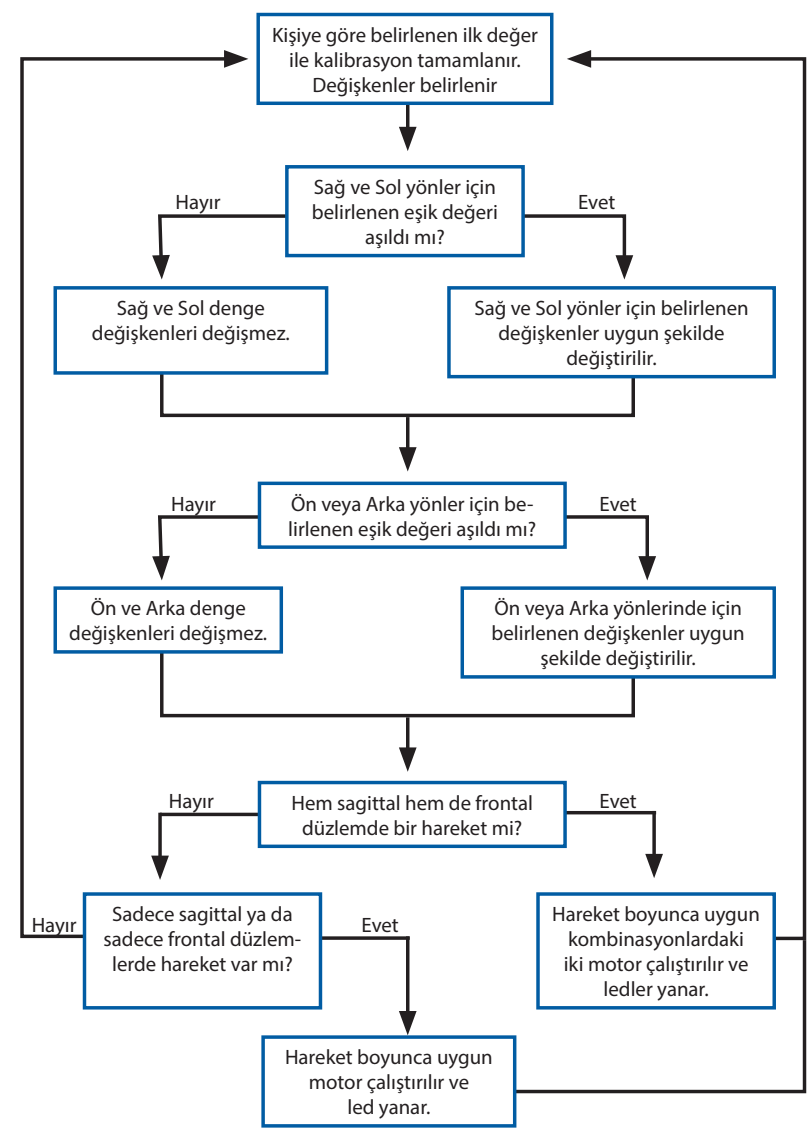

Şekil 2. Kişinin hareket yönüne göre değişken değerlerini belirleyen ve ilgili yönün tayinini ve geribildirimini veren algoritmanın özet akışı.
Tedavinin başında yapılan kalibrasyon, kişinin ayakta ve hareketsiz olarak 3 saniye durması ile yapılmaktadır. Dört ana, dört ara yön olmak üzere toplamda sekiz yöne eğilim belirlenmiştir. Şekil 3'de görüldüğü gibi ön, arka, sağ ve sol ana yönleri oluştururken, ön-sağ, ön-sol, arka-sağ, arka-sol yönleri de ara yönleri oluşturmaktadır. Sagittal düzlemdeki (Şekil 4b) hareketler ön (anterior) ve arka (posterior) yönlerdeki hareketleri kapsarken, frontal düzlemdeki (Şekil 4a) hareketler sağ ve sol yönlerden oluşmaktadır.

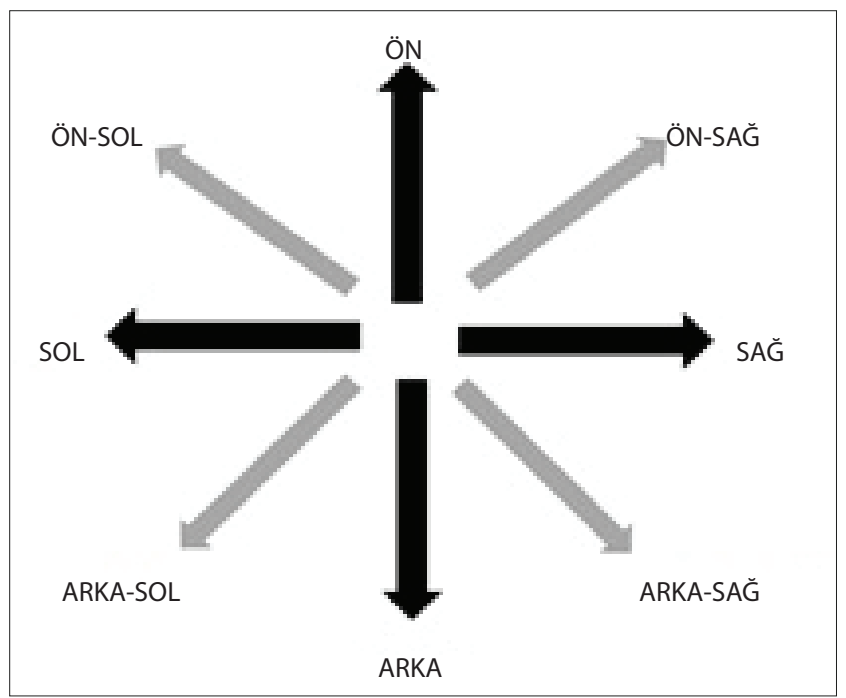

Şekil 3. Dengenin bozulduğu yönlerin gösterimi (siyah oklar ana yön, gri oklar ara yönleri temsil etmektedir).

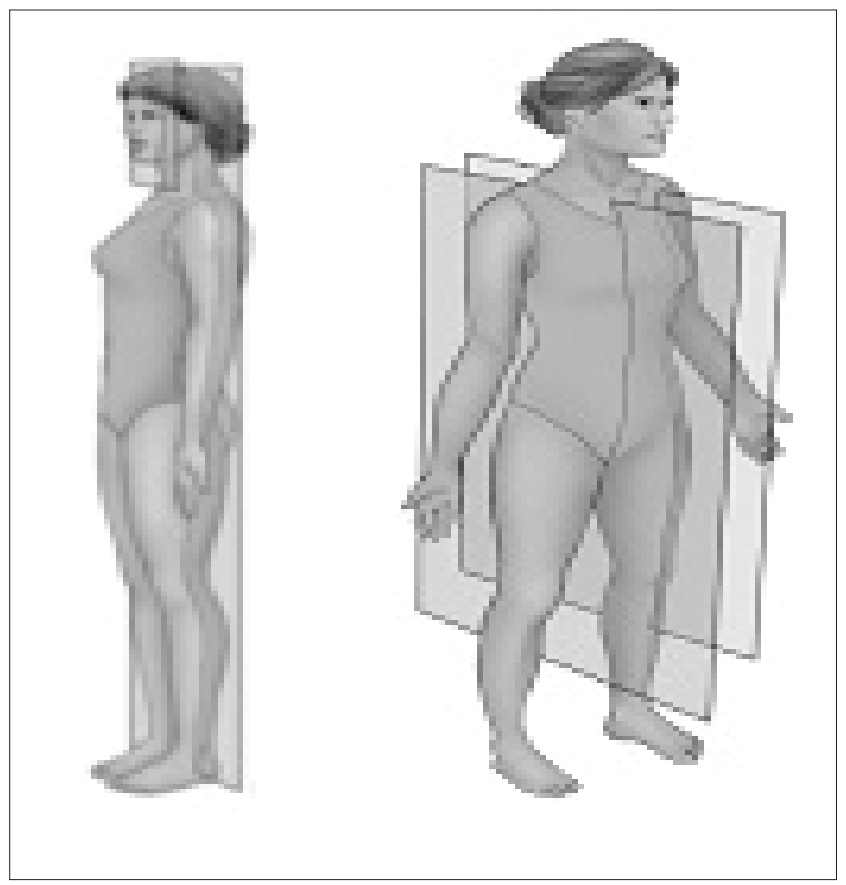

Şekil 4. a, b. Anatomik pozisyonda (a) frontal düzlem (b) sagittal düzlem (Kinesiology: The skeletal system and muscle function ISBN: 978-0-32306944-1'den uyarlanmıştır). 
Autodesk Fusion $360^{\mathrm{TM}}$ CAD (https://www.autodesk.com. tr/products/fusion-360/overview) yazılımı ile tasarlanan ve Formlabs Form $2^{\circ}$ (https://formlabs.com/3d-printers/ form-2/) 3B yazıcısı ile standart siyah reçine kullanılarak elde edilen sensör kılıflarının her biri 25 mikron kalınlığındadır (Şekil 5). Gerçek zamanlı biyolojik geri bildirim mekanizmasının doğrulama testleri Xsens MVN Avinda (Xsens Technologies BV (Hollanda)) ile yapılmıştır (Şekil 1 ve 6). Xsens MVN kablosuz hareket analizi sistemine ait sternuma yerleştirilen IMU sensörü ile bu çalışmada bahsedilen biyolojik geri bildirim mekanizması sağlıkı altı katıımcı ((dört erkek) (ortalama yaş 22 \pm 2 ; ortalama boy: $1,71 \pm 0,05 \mathrm{~m}$; ortalama kilo: $70,8 \pm 15,9 \mathrm{~kg}$, ortalama VKI: $\left.23,9 \pm 2,9 \mathrm{~kg} / \mathrm{m}^{2}\right)$ ) üzerine yerleştirilmiştir. Katılımcılar alt ve üst ekstremitede herhangi bir ameliyat geçirmemiş, anormal yürüme deseni olmayan genç popülasyon içerisinden seçilmiştir. Postürel hizalama eşik değerleri 5-10-15-20 ve $25^{\circ}$ olarak belirlenmiş ve her eşik değeri için 10 ölçüm yapılmıştır. Elde edilen veri iki sistemi karşılaştırma amaçlı olarak analiz edilmiştir. Çalışma Acıbadem Üniversitesi Tıbbi Çalışmalar Etik Kurulu tarafından onaylanmıştır (Etik Kurul 26.10.2017 tarihli, ATADEK 2017-16/10 numaralı kararı).

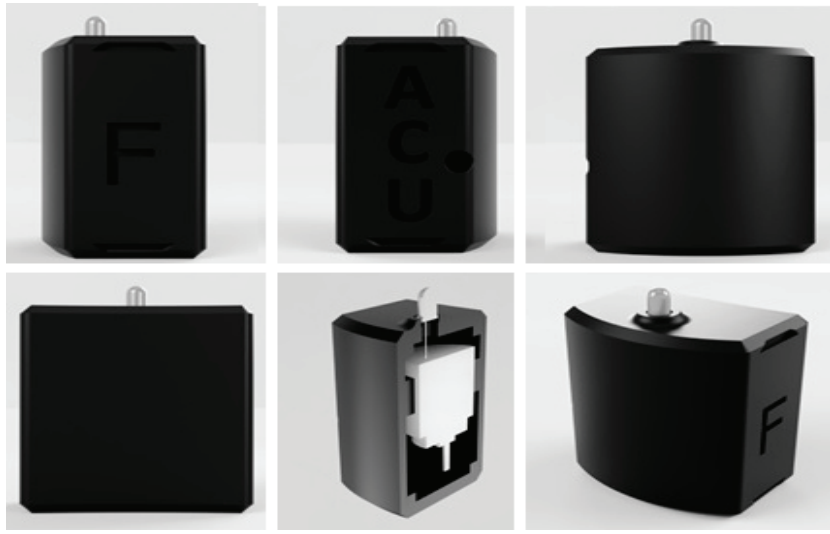

Şekil 5. Kemer üzerine yerleştirilen titreşim motorları için ergonomik 3B yazıcıda üretilen stereolitografi klıfları.

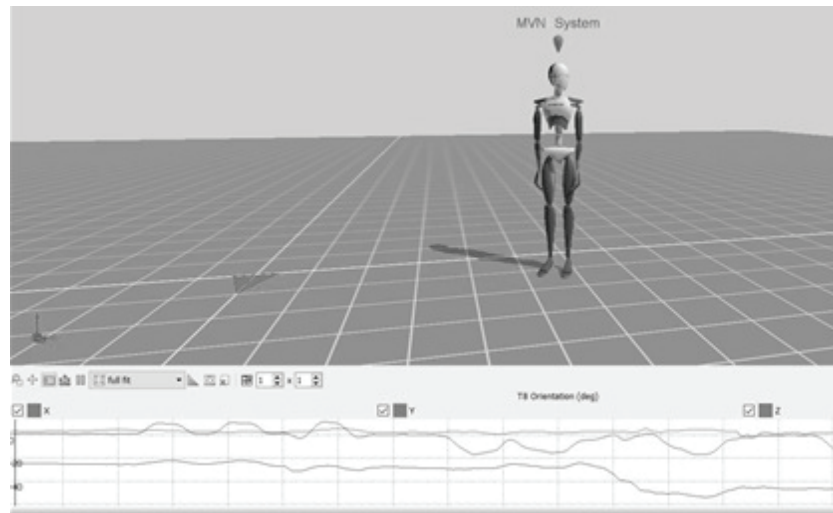

Şekil 6. Xsens MVN ile doğrulama testi (basınç merkezi ve sternum pozisyon okumaları ile postürel hizalama)

\section{Bulgular ve Sonuç}

Geliştirilen denge biyolojik geribildirim sensöründen elde edilen sonuçlar ile Xsens MVN postürel hizalama verisi arasında yüksek korelasyon elde edilmiştir ( $r=0,9994$, $r^{2}=0,987, p<0,05$; Şekil 7). Altı katılımcı ile geliştirilen anlık denge sensöründen ve Xsens MVN'den elde edilen veri kişiler arası bağımsız örneklem t-testi kullanılarak analiz edilmiştir. Deney grubunu geliştirilen sensorden elde edilen veri, kontrol grubunu ise Xsens MVN'den alınan veri oluşturmuştur. Elde edilen sonuçlara göre istatistiksel olarak bu iki grup arasında anlamlı farklılık bulunmamıştır $\left(\mathrm{t}=1.91<\mathrm{t}_{0.025,28}=1,724\right.$ için $\left.\mathrm{p}>0.05\right)$.

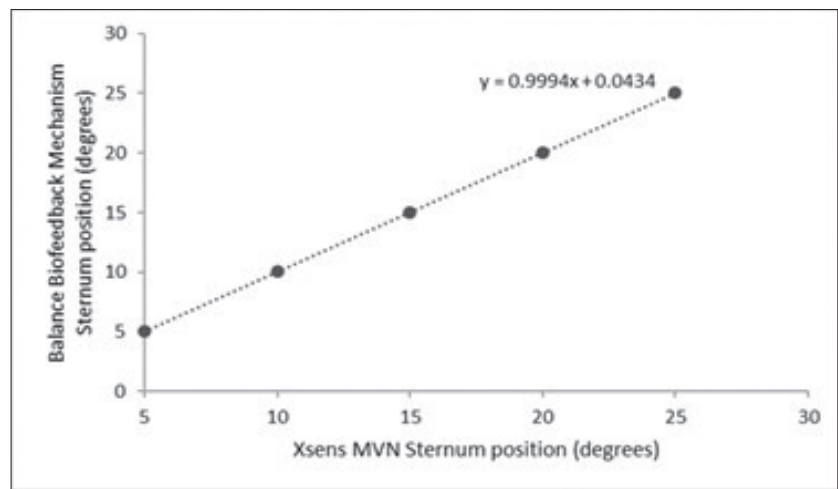

Şekil 7. Xsens MVN ile doğrulama testi korelasyon eğrisi.

Vücudun başarım sağlamadaki motor kontrol tepkisi olan fiziksel aktivite adaptasyonu, çeşitli fizyolojik sistemleri içeren karmaşık bir işlemdir. Biyolojik geri bildirim, kişiye sürekli gerçek zamanlı fizyolojik bilgi sağlayarak öz düzenlemeyi kolaylaştırdığından, aktivitenin yoğun tekrarla ve en iyileştirilmiş olarak gerçekleştirilmesine yardımcı olmaktadır. Sonuç olarak, fiziksel, fizyolojik ve bilişsel durum en iyileştirilerek, vücudun fiziksel aktiviteye olan adaptasyonu sağlanır. Yapılan son çalışmalara göre, biyolojik geribildirim uygulamalarının nörodejeneratif hastalıkların motor rehabilitasyonu için yararlı bir araç olduğu; geri bildirime dayalı tedavilerin hasta katılımını ve motivasyonunu artırdığını, motor fonksiyon alanlarını konvansiyonel tedavi programlarına kıyasla daha etkin iyileştirdiğini ortaya koymaktadır (18-21). Imaizumi ve ark. (2018) (22), gerçek zamanlı ağırlık merkezi değişim görsel geribildiriminin postürel kontrolü iyileştirdiğini belirtmiştir. Benzer şekilde, Semprini ve ark. (2018) (23), geleneksel rehabilitasyon tekniklerinin biyolojik geri bildirim ile birleştirilmesiyle, nörolojik hastalıkların rehabilitasyonunun geleneksel tedavilere göre etkinliğinin artıııldığını ortaya koymuştur. Ribeiro ve ark. (2018) (24), disfonisi olan kadınlarda elektromiyografik geri bildirim ile ses tedavisinin etkinliğini araştırmış, vokal kalitesi ve kas elektriksel 
aktivitesi konusunda olumlu sonuçlar elde etmiştir. Bu bulgular biyolojik geri bildirimin, dış ve iç koşulların ve faaliyetin durumu ile ilgili gerçek zamanlı ve sürekli dinamik bilgi sağlamanın en uygun yollarından biri olduğunu göstermektedir (25).

Fizik tedavi ve rehabilitasyon programının başarısı kişiye özel olarak tasarlanmasına, terapi esnasında hastanın performansının optimal seviyede tutulmasına, hastanın tedaviye uyumuna, rehabilitasyon ekibinin deneyimi ve ekibin hastanın fiziksel gelişimini anlık ve doğru olarak tespit ve takip edebilmesine bağlıdır. Konvansiyonel rehabilitasyon süresince fizik muayene bulguları, hastanın sübjektif geri bildirimleri, eklem hareket açıklığı, kas gücü ve fonksiyonel durumu değerlendiren ölçeklerle yapılmakla birlikte eklem hareketinin biyomekaniği, hastanın anlık hareket kabiliyeti ve daha önceki terapi sonuçlarına kıyasla anlık olarak elde edilen gelişmeyi niceliksel olarak değerlendirilmesini sağlayamamaktadır. Bu nedenle konvansiyonel rehabilitasyon uygulamalarının yenilikçi mühendislik uygulamalarıyla desteklenmesi büyük önem taşımaktadır.

Geliştirilen biyolojik geri bildirim mekanizması tanı, tedavi ve destek amaçlı olarak fizik tedavi ve rehabilitasyon

\section{Kaynaklar}

1. Alexander RM. Bipedal animals and their differences from humans. J Anat 2004;204:321-30. https://www.ncbi.nlm.nih.gov/pmc/articles/ PMC1571302/

2. Pau M, Ibba PM, Attene G. Fatigue-induced balance impairment in young soccer players. J Athl Train 2014;49:454-61. [CrossRef]

3. Friedrich EVC, Mc Farland DJ, Neuper C, Vaughan TM, Brunner $P$, Wolpaw JR. A scanning protocol for a sensorimotor rhythmbased brain-computer interface. Biol Psychol 2009;80:169-75. [CrossRef]

4. Bohnsack Mc Lagan NK, Cusumano JP, Dingwell JB. Adaptability of stride-to-stride control of stepping movements in human walking. J Biomech 2016;49:229-37. [CrossRef]

5. Bourne RB, Chesworth BM, Davis AM, Mahomed NN, Charron KDJ. Patient satisfaction after total knee arthroplasty: who is satisfied and who is not?. Clin Orthop Relat Res 2010;468:57-63. [CrossRef]

6. Christensen JC, La Stayo PC, Marcus RL, Stoddard GJ, Bo Foreman $\mathrm{K}$, Mizner RL, et al. Visual knee-kinetic biofeedback technique normalizes gait abnormalities during high-demand mobility after total knee arthroplasty. Knee 2018;25:73-82. [CrossRef]

7. Kondilopoulos N, Rousanoglou EN, Boudolos KD. Inertial sensing of the motion speed effect on the sit-to-walk activity. Gait Posture 2018:61:111-6. [CrossRef]

8. Jiang GP, Jiao XB, Wu SK, Ji ZQ, Liu WT, Chen X, Wang HH. Balance, Proprioception, and Gross Motor Development of Chinese Children Aged 3 to 6 Years. J Mot Behav 2018;50:343-52. [CrossRef]

9. Collins DF, Refshauge KM, Todd G, Gandevia SC. Cutaneous receptors contribute to kinesthesia at the index finger, elbow, and knee. J Neurophysiol 2005;94:1699-706. [CrossRef] süreçlerinde kullanılabilecek yenilikçi bir tıbbi cihazdır. Hedef, hastaların sinir sisteminin hızlı ve optimal kas kasılması üretme, koordinasyonu / dengeyi geliştirme ve hareket kalıplarını ve becerilerini geri kazanma potansiyelini geliştirmek ile fizik tedavi sürecinin etkinliğini artırmaktır. Bu da ancak tekrarlanabilirliliği yüksek ve kişinin intiyacına ve kısıtlarına yönelik olarak oluşturulan rehabilitasyon programlarıyla elde edilebilir. Hasta uyarlamalı rehabilitasyon ve biyolojik geribildirim sistemi hastanın fizik tedaviye olan katılımını azami seviyeye çıkarmak ve motivasyonu arttırmak için çok önemlidir. Rehabilitasyon sırasında hastaya ve fizik tedavi ekibine geri bildirim sağlanması sürecin etkinliğini ve hastalığın klinik takibini iyileştirmektedir (26). Sağlanan gerçek zamanlı bilgi hastanın daha önce santral sinir sisteminin otomatik bir cevabı olarak gördüğü fiziksel süreçlerin kontrolünü ele almasını sağlamaktadır. Bunu yaparken de işlevsel görevler sırasında doğruluğu ve rehabilitasyonda hasta katılımı artırılabilmektedir. Elde edilen ön sonuçlara göre biyolojik geri bildirim mekanizmaları ile desteklenen kişiselleştirilmiş tedavi programlarının hastaların motivasyonunu ve rehabilitasyon sırasında fizik tedavinin etkinliğini artırabileceği ve hastanın optimal performansını daha uzun süre koruyabileceği ön görülmektedir.

10. Daffertshofer A, Lamoth CJ, Meijer OG, Beek PJ. Principal components analysis in studying coordination and variability: A tutorial. Clin Biomech 2004;19:415-28. [CrossRef]

11. Guo L, Xiong S. Accuracy of Base of Support Using an Inertial Sensor Based Motion Capture System. Sensors (Basel) 2017;17:2091. [CrossRef]

12. Segers V, Aerts $P$, Lenoir $M$, De Clercq $D$. Spatiotemporal characteristics of the walk-to-run and run-to-walk transition when gradually changing speed. Gait Posture 2006;24:247-54. [CrossRef]

13. Fothergill S. Examining the effect of real-time visual feedback on the quality of rowing technique. Procedia Eng 2010;2:3083-8 [CrossRef]

14. Hiley MJ, Yeadon MR. Optimisation of high bar circling technique for consistent performance of a triple piked somersault dismount. J Biomech 2008;41:1730-5. [CrossRef]

15. NovacheckTF. The biomechanics of running. Gait Posture 1998;7:7795. [CrossRef]

16. Barra J, Pérennou D, Thilo KV, Gresty MA, Bronstein AM. The awareness of body orientation modulates the perception of visual vertical. Neuropsychologia 2012;50:2492-8. [CrossRef]

17. Assaiante C, Barlaam F, Cignetti F, Vaugoyeau M. Body schema building during childhood and adolescence: a neurosensory approach. Neurophysiol Clin 2014;44:3-12. [CrossRef]

18. Barrios JA, Crossley KM, Davis IS. Gait retraining to reduce the knee adduction moment through real-time visual feedback of dynamic knee alignment. J Biomech 2010;43:2208-13. [CrossRef]

19. Christiansen CL, Bade MJ, Davidson BS, Dayton MR, Stevens-Lapsley JE. Effects of Weight-bearing biofeedback training on functional movement patterns following total knee arthroplasty: a randomized controlled trial. J Orthop Sports Phys Ther 2015;45:647-55. [CrossRef] 
20. Kearney E, Shellikeria S, Martino R, Yunusova Y. Augmented visual feedback-aided interventions for motor rehabilitation in Parkinson's disease: a systematic review. Disabil Rehabil 2019;41:995-1011. [CrossRef]

21. Pogonchenkova IV, Khan MA, Korchazhkina NB, Novikova EV, Bokova IA, Lyan NA. The application of the physical factors for the medical rehabilitation of the children presenting with neurogenic dysfunction of the bladder. Vopr Kurortol Fizioter Lech Fiz Kult 2017;94:53-8. [CrossRef]

22. Imaizumi S, Asai T, Hiromitsu K, Imamizu H. Voluntarily controlled but not merely observed visual feedback affects postural sway. Peer J 2018;6:e4643. [CrossRef]

23. Semprini M, Laffranchi $M$, Sanguineti V, Avanzino L, Icco RD, Michieli LD, Chiappalone M. Technological Approaches for Neurorehabilitation: From Robotic Devices to Brain Stimulation and Beyond. Front Neurol 2018;9. [CrossRef]
24. Ribeiro VV, de Oliveira AG, da Silva Vitor J, Ramos AC, Brasolotto AG, Silverio KCA,. Effectiveness of Voice Therapy Associated With Electromyographic Biofeedback in Women With Behavioral Dysphonia: Randomized Placebo-Controlled Double-Blind Clinical Trial. J Voice 2019;33:381.e11-22. [CrossRef]

25. Smits BL, Polman RC, Otten B, Pepping GJ, Hettinga FJ. Cycling in the Absence of Task-Related Feedback: Effects on Pacing and Performance. Front Physiol 2016;10;7:348. [CrossRef]

26. Meyns $P$, de Mettelinge TR, van der Spank J, Coussens M, Van Waelvelde $\mathrm{H}$. Motivation in pediatric motor rehabilitation: A systematic search of the literature using the self-determination theory as a conceptual framework. Dev Neurorehabil 2018;21:37190. [CrossRef] 